\title{
Lyme and associated tick-borne diseases: global challenges in the context of a public health threat
}

\author{
Christian Perronne* \\ Yvelines, Garches, France \\ ${ }^{*}$ Correspondence: c.perronne@rpc.aphp.fr \\ Edited by: \\ Muriel Vayssier-Taussat, Institut National de la Recherche Agronomique, France \\ Reviewed by: \\ Leona Gilbert, University of Jyväskylä, Finland \\ Josette Raymond, Université Paris Descartes, France
}

Infectious Diseases Unit, Hôpitaux Universitaires Paris-lle de France-Ouest, Assistance Publique - Hôpitaux de Paris, University of Versailles - Saint Quentin en

Keywords: Lyme disease, Borrelia burgdorferi, Borrelia miyamotoi, novel borreliae, diagnosis, coinfections, tick borne disease, occult infection

Lyme disease, caused by Borrelia burgdorferi and transmitted by ticks, was initially considered a recent, rare and regional occurrence. We now have evidence that very similar bacteria infected humans in Europe during the ice age (Keller et al., 2012). Evidence-based data are scarce therefore many aspects of the disease remain controversial (Auwaerter et al., 2011; Lee and Vielmeyer, 2011; Perronne, 2012), but in 2013 the Centers for Disease Control and Prevention (CDC) revised their annual estimates from 30,000 cases to 300,000 cases in the USA alone. Having dramatically increased their numbers, the CDC are now calling Lyme disease "a tremendous public health problem in the United States" (CDC, 2011).

The lack of a gold standard for diagnosis makes producing accurate statistics difficult. Some pathogenic strains belonging to the B. burgdorferi sensu lato complex have a worldwide distribution, yet they are rarely considered or tested for (Varela et al., 2004; Lopes de Carvalho et al., 2009; Rudenko et al., 2009; Stanek and Reiter, 2011; Branda and Rosenberg, 2013; Clark et al., 2013; Lee et al., 2014; Margos et al., 2014). Borrelia miyamotoi, for instance, phylogenetically close to relapsing fever borreliae, is now recognized as a cause of Lyme-like disease and relapsing fever in Asia, Europe and North America. It usually does not cross react with $B$. burgdorferi tests (Branda and Rosenberg, 2013; Lee et al., 2014). A novel isolate of Borrelia has been isolated by PCR in a post-treatment serum from a patient with neurologic Lyme disease (Lee et al., 2014).
These recent historical, geographical and microbial data should prompt the medical community to realize that cases of persisting post tick-bite syndromes are probably due to multiple pathogens and that these occult infections will require a new approach if not an actual paradigm shift.

\section{DIAGNOSTIC PITFALLS IN ROUTINE PRACTICE}

Classical forms of Lyme disease are usually easy to manage, but these medical conditions with pleomorphic non specific symptoms may prove confusing to physicians (Strle and Stanek, 2009). Lyme disease may mimic chronic inflammatory or degenerative diseases, including a wide range of auto-immune diseases. Although practitioners from every medical specialty are likely to have encountered cases of Lyme disease, they may have failed to recognize it, no matter how skilled they are. A major obstacle is that only $30 \%$ of the patients report a history of tick bite and only $70-80 \%$ present with a primary erythema migrans, the pathognomonic initial lesion. This lesion may go unrecognized, or be mistaken for an "insect bite" or an "allergic rash." Mini-erythema migrans are less likely to be diagnosed. Secondary erythema migrans are observed in approximately $50 \%$ of cases. Bacteriologic and pathologic analogies have been reported between tertiary neuroborreliosis and tertiary neurosyphilis (Miklossy, 2012). Syphilis, once well-known as the great imitator, gives us a good historical model for the concept of occult infection.
OCCULT INFECTIONS AND THEIR ROLE IN THE PATHOPHYSIOLOGY OF SOME DISEASES OF UNCLEAR ETIOLOGY

Charles Nicolle, working at the Institut Pasteur in Tunis and Nobel prize winner in 1928, showed great interest in the concept of occult infections ("les infections inapparentes") like typhus, syphilis, and relapsing fever (Borrelia recurrentis) (Nicolle, 1993). Relapsing fever due to another species of Borrelia (B. crocidurae) is still a public health concern in some parts of Africa, and the recently discovered B. miyamotoi may also become a similar problem in Asia, Europe and America (Schwan et al., 2012; Branda and Rosenberg, 2013; Lee et al., 2014). Peptic ulcer disease is another example of the hidden link between an occult infection with another spiral-shaped bacterium, Helicobacter pylori, and a chronic disorder. B. burgdorferi may persist in tissues even after antibiotic treatments, as animal models have shown (Straubinger et al., 1997; Straubinger, 2000; Hodzic et al., 2008; Yrjänäinen et al., 2010; Embers et al., 2012). In fact dormant persister cells of bacteria from different genera can escape the bactericidal effect of antibiotics and be responsible for latent infections (Phillips et al., 1998; Hunfeld et al., 2005; Lewis, 2007; Lee et al., 2014). Clinicians have no diagnostic tests to check for the persistence of live borreliae. B. burgdorferi, having a complex genetic structure, is a highly adaptable organism capable of evading immune response through different processes. It can survive extracellularly and intracellularly (Brorson and Brorson, 1998; Murgia and Cinco, 2004). 
The complexity of Lyme disease requires high quality diagnostic methods, yet serology is the only diagnostic tool widely used.

\section{SEROLOGY, THE CURRENT MAIN DIAGNOSTIC METHOD}

Physicians should be made aware that, in the presence of primary erythema migrans, serology will often be negative therefore diagnosis should be clinical (Wormser, 2006). However, many practitioners are still under the misconception that a positive serology is required for early stage diagnosis. For later stages of the disease serology remains the main diagnostic tool. The Infectious Diseases Society of America (IDSA) and the European Concerted Action on Lyme Borreliosis (EUCALB) are recommending a twotier testing approach, the first step being an ELISA using whole sonicate of the in vitro cultured tick-derived strain B31 of Borrelia burgdorferi (EUCALB, 1997; Wormser et al., 2006). If positive, confirmation by immunoblot testing IgG and IgM is required. According to these guidelines, immunoblot is not to be performed if the ELISA is negative. However, in 2011, the CDC modified their case definition and included single-tier IgG immunoblot seropositivity as a diagnostic criterion for Lyme disease (CDC, 2013). But most practitioners still use the two-tier system despite the poor sensitivity of ELISA tests, ranging from 34 to 70.5 (Marangoni et al., 2005; Aguero-Rosenfeld, 2008; Ang et al., 2011; Wojciechowska-Koszko et al., 2011). Calibration of the tests is a crucial issue.

\section{CALIBRATION OF SEROLOGY}

When Lyme serology was developed, no reliable method was available to be used as a gold standard for comparison. As most of the signs and symptoms are non-specific, no reliable clinical diagnostic score could be established. The low yield of culture and the difficulty involved in using the technique routinely were another major obstacle. A pragmatic cut-off level for the serologic tests had to be determined arbitrarily on blood donors (EUCALB, 1997; Assous, 2007). In the late seventies, when Lyme disease was first discovered, it was understandably thought to be a rare and regional phenomenon. Therefore, a low prevalence was set as experts were afraid the serologies would produce too many false positive diagnoses (EUCALB, 1997; Assous, 2007). Patients and control populations are ill-defined with a high variability in predictive positive and negative values from one test to another. Culture of B. burgdorferi or detection of its genome by polymerase chain reaction (PCR) may occasionally confirm the clinical diagnosis in seronegative patients, however none of these methods are sensitive enough to be considered reliable diagnostic methods, especially in routine practice (Schutzer et al., 1990; Nields and Kveton, 1991; Chmielewska-Badora et al., 2006; Brunner, 2006; Assous, 2007; HollWieden et al., 2007; Aguero-Rosenfeld, 2008; Dietrich et al., 2008; Wallet et al., 2008). As a result, many patients suffering signs and symptoms compatible with Lyme disease, but whose test is negative, are falling by the wayside.

\section{CLINICAL AND EPIDEMIOLOGICAL CONSEOUENCES OF NEGATIVE SEROLOGY}

Modern medical practice expects to rely on evidence. Most physicians would not consider diagnosing Lyme disease without serological proof. Yet the failure to diagnose seronegative neuroborreliosis, especially the acute or severe forms, can have dire consequences including chronic neurologic sequelae or even death. A review of the literature shows that a diagnosis of Lyme neuroborreliosis is often difficult to prove (Blanc et al., 2007; Bennet et al., 2008; Tveitnes et al., 2009; Makhani et al., 2011). The sensitivity of intrathecal antibody index (measuring specific antibodies within the cerebro-spinal fluid) ranges from 55 to $80 \%$. In a Swedish study, antibodies were present in serum of only $23 \%$ of children with neuroborreliosis (Bennet et al., 2008). Cognitive tests or SPECT brain imaging may help to provide objective evidence (Tager et al., 2001; RocheLanquetot et al., 2008; Fallon et al., 2009; Donta et al., 2012). Pragmatic diagnostic criteria including response to empiric antibiotic treatment are used to diagnose neuroborreliosis (Blanc et al., 2007). Should this strategy be recommended in other clinical presentations as well? In fact some clinicians will not hesitate to classify as Lyme disease cases, seronegative patients with a highly compatible clinical picture, provided other diagnoses have been ruled out. In a major clinical trial on Lyme disease, $40 \%$ of the enrolled patients were seronegative. These patients had a history of erythema migrans, neurologic or cardiac symptoms, radiculoneuropathy or arthritis (Klempner et al., 2001). Clinicians, often unaware of the difficulties involved in diagnosing Lyme disease, will fall back on "weak" alternative diagnoses ("viral," "idiopathic," "autoimmune," "degenerative," "inflammatory," or "psychosomatic") (Kennedy, 2013). New techniques are needed to accurately assess these patients. This current overreliance on inaccurate testing procedures not only flaws the diagnosis of individual patients but it also has epidemiological consequences especially as new species and variants continue to be identified on all continents (Hao et al., 2011; Rudenko et al., 2011).

\section{POSSIBLE CAUSES OF SERONEGATIVITY}

Several factors leading to seronegativity have been identified in confirmed cases of Lyme disease: (i) the arbitrary cutoff level of tests, (ii) the sequestration of antibodies in immune complexes, (iii) the wide variety of species and subspecies of Borrelia that co-exist in different parts of the world, and (iv) coinfections with other pathogens which may be responsible for some or all of the symptoms or which may alter the immune response (Schutzer et al., 1990; Brunner, 2006). The complex $B$. burgdorferi sensu lato includes (Table 1): $B$. burgdorferi sensu stricto (including genetic diversity), B. afzelii, B. garinii (several serotypes) and additional species isolated in different parts of the world (Rudenko et al., 2009, 2011; Ogden et al., 2011). Some of these species have been isolated in symptomatic patients (Varela et al., 2004; Lopes de Carvalho et al., 2009; Rudenko et al., 2009; Stanek and Reiter, 2011; Branda and Rosenberg, 2013; Clark et al., 2013; Lee et al., 2014; Margos et al., 2014). B. spielmanii may cause early skin disease (Stanek and Reiter, 2011). B. bavariensis, B. bisettii, $B$. valaisiana, B. americana, $B$. andersonii, $B$. lonestari and more recently B. kurtenbachii have been isolated from patients with Lyme-like diseases (Varela et al., 2004; Rudenko et al., 2009; Rizzoli et al., 2011; Stanek and Reiter, 2011; Clark et al., 2013). The pathogenic role of $B$. 
Table 1 | Bacteria responsible for Lyme or Lyme-like disease and other Borrelia sp. belonging to the Borrelia burgdorferi sensu lato complex, and other tick-borne micro-organisms isolated in humans.

\title{
Bacteria responsible for Lyme disease belonging to the Borrelia burgdorferi sensu lato complex
}
Borrelia burgdorferi sensu stricto (including genetic diversity)
North America, Europe, North Africa
Borrelia afzelii
Europe, Asia
Borrelia garinii (several serotypes)
Europe, Asia, North Africa
Borrelia bavariensis (previously B. garinii OspA serotype 4)

\section{Bacteria responsible for Lyme-like disease}

$\begin{array}{ll}\text { Borrelia lonestari } & \text { North America } \\ \text { Borrelia miyamotoi (also cause of relapsing fever) } & \text { Europe, Asia, North America } \\ \text { Non-identified spirochete } & \text { Brazil }\end{array}$

\section{Bacteria occasionally isolated in cases of Lyme-like disease}

Borrelia spielmanii

Borrelia bisettii

Borrelia andersonii

Borrelia valaisiana

Borrelia americana

Borrelia kurtenbachii

Novel Borrelia sp. close to relapsing fever borreliae (Lee et al., 2014)

Other Borrelia sp., belonging to the Borrelia burgdorferi sensu lato complex with unknown or poorly documented pathogenicity
$\begin{array}{ll}\text { Borrelia japonica } & \text { Borrelia turdi } \\ \text { Borrelia sinica } & \text { Borrelia tanukii } \\ \text { Borrelia lusitaniae (vasculitis?) } & \text { Borrelia californiensis } \\ \text { Borrelia carolinensis } & \text { Borrelia yangtze }\end{array}$

\section{Borrelia sp. responsible for relapsing fever \\ Louse-borne relapsing fever \\ Borrelia recurrentis \\ Tick-borne relapsing fever \\ At least 15 Borrelia sp. including \\ Borrelia crocidurae (Africa) \\ Borrelia miyamotoi (also cause of Lyme-like disease)}

\section{Other human tick-borne infections \\ PARASITES}

Babesia divergens

\section{BACTERIA}

Ehrlichia chaffeensis

Rickettsia sp.

Francisella tularensis

\section{VIRUSES}

\author{
Babesia microti \\ Anaplasma phagocytophilum \\ Coxiella burnetii \\ Candidatus Neoehrlichia mikurensis
}

Several Flaviviridae (including Tick-borne encephalitis virus)

Bunyaviridae (Crimean-Congo hemorrhagic fever)

lusitaniae, isolated in a case of vasculitis, remains to be substantiated (Rudenko et al., 2009). Despite such diversity in strains, most of the commercially available tests still rely on the original 1982 Massachusetts B31 isolate of B. burgdorferi. No diagnostic tool is available for routine detection of B. miyamotoi (Branda and Rosenberg, 2013; Lee et al., 2014). Coinfections with other microbes add to the complexity of these illnesses (Table 1). Among patients with early Lyme disease in the USA, $2-12 \%$ were found to also have human granulocytic anaplasmosis, and 2-40\% babesiosis (Wormser et al., 2006). In Brazil, a Lyme-like syndrome, due to the tick Amblyomma, has been described and mobile non cultivable spirochetes could be visualized in patients' blood using a dark field microscope (Mantovani et al., 2007). A new tick-borne bacterial pathogen, Candidatus Neoehrlichia mikurensis, was reported in Switzerland (Fehr et al., 2010). An illustration of the limits of serology is the Scottish example: the sensitivity of the immunoblot was improved by using local
Scottish strains of Borrelia (Mavin et al., 2007, 2009).

\section{CONCLUSION AND PERSPECTIVES}

The numerous complexities of Lyme disease make it an extremely difficult illness to fully comprehend. It remains a diagnostic challenge even for the best informed of clinicians. The lack of a gold standard for diagnosis renders the management of patients difficult and seriously hinders our ability to produce accurate statistics, especially as very similar syndromes could 
be due to other species of Borrelia. In some patients suffering from syndromes of unclear origin, following tick bite, other microbial agents could also be playing a role. Lyme disease has now entered the political debate as shown by the amendment (Section 54.1-2963.2) voted in 2013 by the State of Virginia, USA, that compels physicians to inform their patients that the "current laboratory testing for Lyme disease can be problematic." The fact that politicians are being called upon to rule on these matters should prompt scientists to regain control of the situation. Politicians should instead become aware of the necessity to fund research and facilitate the setting up of independent international working groups. Reliable testing is essential to investigate the many syndromes of unclear origin that may mimic many other medical disorders. Proper fundamental and clinical research is urgently needed as it would be the most cost effective way of ensuring that patients are accurately diagnosed and that the best therapeutic strategies are decided upon (Stricker and Johnson, 2014). Development of new diagnostic methods is badly needed. New PCR methods and new genomic techniques, such as high throughput sequencing, could prove promising in identifying the complex mix of microbial agents that are probably involved (Vayssier-Taussat et al., 2013; Lee et al., 2014). Next generation sequencing allowed the identification of various bacteria from Ixodes ricinus ticks in France: Anaplasma phagocytophilum, Bartonella henselae, B. grahamii, Borrelia afzelii, B. garinii, B. burgdorferi, B. miyamotoi, Candidatus Neoerlichia mikurensis, Ehrlichia canis, Rickettsia canadensis, $R$. felis, and $R$. helvetica (Vayssier-Taussat et al., 2013). These new techniques should be applied to human samples. Other variables, such as genetic, environmental, or auto-immune factors should also be studied. The name "Lyme disease" is too restrictive as it focuses and fuels the controversy. A new term should be agreed upon for these syndromes with possible infectious involvement, often following tick bites. Closer collaboration between epidemiologists, microbiologists, immunologists, geneticians, environmental scientists, veterinarians, entomologists, and clinicians is needed to identify the main agents that could be causing these occult infections and to determine strain pathogenicity. A new multidirectional approach is crucial in order to widen the field of research and to move forward.

\section{ACKNOWLEDGMENT}

The author thanks Nelly Pointis for her help with editing.

\section{REFERENCES}

Aguero-Rosenfeld, M. E. (2008). Lyme disease: laboratory issues. Infect. Dis. Clin. North Am. 22, 301-313. doi: 10.1016/j.idc.2007.12.005

Ang, C. W., Notermans, D. W., Hommes, M., Simoons-Smit, A. M., and Herremans T. (2011). Large differences between test strategies for the detection of anti-Borrelia antibodies are revealed by comparing eight ELISAs and five immunoblots. Eur. J. Clin. Microbiol. Infect. Dis. 30, 1027-1032. doi: 10.1007/s10096-0111157-6

Assous, M. V. (2007). Laboratory methods for the diagnosis of clinical forms of Lyme borreliosis (in French). Med. Mal. Infect. 37, 487-495. doi: 10.1016/j.medmal.2006.01.019

Auwaerter, P. G., Bakken, J. S., Dattwyler, R. J., Dumler, J. S., Halperin, J. J., McSweegan, E., et al. (2011). Antiscience and ethical concerns associated with advocacy of Lyme disease. Lancet Infect. Dis. 11, 713-719. doi: 10.1016/S14733099(11)70034-2

Bennet, R., Lindgren, V., and ZweygbergWirgart, B. (2008). Borrelia antibodies in children evaluated for Lyme neuroborreliosis. Infection 36, 463-466. doi: 10.1007/s15010-0086259-4

Blanc, F., Jaulhac, B., Fleury, M., de Sèze, J., de Martino, S. J., Rémy, V., et al. (2007). Relevance of the antibody index to diagnose Lyme neuroborreliosis among seropositive patients. Neurology 69, 953-958. doi: 10.1212/01.wnl.0000269672. 17807.e0

Branda, J. A., and Rosenberg, E. (2013). S. Borrelia miyamotoi: a lesson in disease discovery. Ann. Intern. Med. 159, 61-62. doi: 10.7326/0003-4819159-1-201307020-00009

Brorson, O., and Brorson, S. H. (1998). In vitro conversion of Borrelia burgdorferi to cystic forms in spinal fluid, and transformation to mobile spirochetes by incubation in BSK-H medium. Infection 26, 144-150. doi: 10.1007/BF02 771839

Brunner, M. (2006). Report refuting value of immune complexes to diagnose Lyme disease is invalid. Clin. Vaccine Immunol. 13, 304-306. doi: 10.1128/CVI.13.2.304-306.2006

CDC. (2011). Centers for Disease Control and Prevention. National notifiable Diseases Surveillance System. Lyme disease - Borrelia Burgdorferi - 2011 Case Definition. Available online at: wwwn.cdc.gov/NNDSS/script/casedef.aspx (Accessed March 24, 2014).

CDC. (2013). Centers for Disease Control and Prevention. Media Relations. CDC Provides Estimate of Americans Diagnosed with Lyme Disease Each Year. Available online at: www.cdc.gov/media/releases/2013/p0819-lymedisease.html (Accessed March 24, 2014).

Chmielewska-Badora, J., Cisak, E., Wojcik-Fatla, A., Zwolinski, J., Buczek, A., and Dutkiewicz, J. (2006). Correlation of tests for detection of Borrelia burgdorferi sensu lato infection in patients with diagnosed borreliosis. Ann. Agric. Environ. Med. 13, 307-311.

Clark, K. L., Leydet, B., and Hartman, S. (2013). Lyme borreliosis in human patients in Florida and Georgia, USA. Int. J. Med. Sci. 10, 915-931. doi: 10.7150/ijms.6273

Dietrich, T., Geissdörfer, W., Schlötzer-Schrehardt, U., Holbach, L., Schoerner, C., and Seitz, B. (2008). Borrelia-associated crystalline keratopathy with intracorneal detection of Borrelia garinii by electron microscopy and polymerase chain reaction. Cornea 27, 498-500. doi: 10.1097/ICO.0b013e318162a8f5

Donta, S. T., Noto, R. B., and Vento, J. A. (2012). SPECT brain imaging in chronic Lyme disease. Clin. Nucl Med 37, 219-222. doi: 10.1097/RLU.0b013e318262ad9b

Embers, M. E., Barthold, S. W., Borda, J. T., Bowers, L., Doyle, L., Hodzic, E., et al. (2012). Persistence of Borrelia burgdorferi in Rhesus macaques following antibiotic treatment of disseminated infection. PLoS ONE 7:e29914. doi: 10.1371/journal.pone.0029914. Erratum PLOS ONE 7. doi: 10.1371

EUCALB. (1997). European Concerted Action on Lyme Borreliosis, Diagnosis: Serology: Minimum Standards. Available online at: www.eucalb.com (Accessed March 24, 2014).

Fallon, B. A., Lipkin, R. B., Corbera, K. M., Yu, S., Nobler, M. S., Keilp, J. G., et al. (2009). Regional cerebral blood flow and metabolic rate in persistent Lyme encephalopathy. Arch. Gen. Psychiatry 66, 554-563. doi: 10.1001/archgenpsychiatry.2009.29

Fehr, J. S., Bloemberg, G. V., Ritter, C., Hombach, M., Lüscher, T. F., Weber, R., et al. (2010). Septicemia caused by tick-borne bacterial pathogen Candidatus Neoehrlichia mikurensis. Emerging Infect. Dis. 16, 1127-1129. doi: 10.3201/eid1607.091907

Hao, Q., Hou, X., Geng, Z., and Wan, K. (2011). Distribution of Borrelia burgdorferi sensu lato in China. J. Clin. Microbiol. 49, 647-650. doi: 10.1128/JCM.00725-10

Hodzic, E., Feng, S., Holden, K., Freet, K. J., and Barthold, S. W. (2008). Persistence of Borrelia burgdorferi following antibiotic treatment in mice. Antimicrob. Agents Chemother. 52, 1728-1736. doi: 10.1128/AAC.01050-07

Holl-Wieden, A., Suerbaum, S., and Girschick, H. J. (2007). Seronegative Lyme arthritis. Rheumatol. Int. 27, 1091-1093. doi: 10.1007/s00296-0070333-6

Hunfeld, K. P., Ruzic-Sabljic, E., Norris, D. E., Kraiczy, P., and Strl, F. (2005). In vitro susceptibility testing of Borrelia burgdorferi sensu lato isolates cultured from patients with erythema migrans before and after antimicrobial chemotherapy. Antimicrob. Agents Chemother. 49, 1294-1301. doi: 10.1128/AAC.49.4.12941301.2005

Keller, A., Graefen, A., Ball, M., Matzas, M., Boisguerin, V., Maixner, F., et al. (2012). New 
insights into the Tyrolean Iceman's origin and phenotype as inferred by whole-genome sequencing. Nat. Commun. 3:698. doi: 10.1038/ ncomms 1701

Kennedy, A. G. (2013). Differential diagnosis and the suspension of judgment. J. Med. Philos. 38, 487-500. doi: 10.1093/jmp/jht043

Klempner, M. S., Hu, L. T., Evans, J., Schmid, C. H., Johnson, G. M., Trevino, R. P., et al. (2001). Two controlled trials of antibiotic treatment in patients with persistent symptoms and a history of Lyme disease. N. Engl. J. Med. 345, 85-92. doi: 10.1056/NEJM200107123 450202

Lee, D. J., and Vielmeyer, O. (2011). Analysis of overall level of evidence behind infectious diseases society of america practice guidelines. Arch. Intern. Med. 171, 18-22. doi: 10.1001/archinternmed. 2010.482

Lee, S. H., Vigliotti, J. S., Vigliotti, V. S., Jones, W., and Shearer, D. M. (2014). Detection of Borreliae in archived sera from patients with clinically suspect Lyme disease. Int. J. Mol. Sci. 15, 4284-4298. doi: 10.3390/ijms 15034284

Lewis, K. (2007). Persister cells, dormancy and infectious disease. Nature 5, 48-56. doi: 10.1038/nrmicrol557

Lopes de Carvalho, I., Fonseca, J. E., Marques, J. G., Ullmann, A., Hoigaard, A., Zeidner, N., et al. (2009). Vasculitis-like syndrome associated with Borrelia lusitaniae infection. Clin. Rheumatol. 27, 1587-1591. doi: 10.1007/s10067-008-1012-z

Makhani, N., Morris, S. K., Page, A. V., Brophy, J., Lindsay, L. R., Banwell, B. L., et al. (2011). A twist on Lyme: the challenge of diagnosing European Lyme neuroborreliosis. J. Clin. Microbiol. 49, 455-457. doi: 10.1128/JCM. 01584-10

Mantovani, E., Costa, I. P., Gauditano, G., Bonoldi, V. L. N., Higuchi, M. L., and Yoshinari, N. H. (2007). Description of Lyme disease-like syndrome in Brazil. Is it a new tick borne disease or Lyme disease variation? Braz. J. Med. Biol. Res. 40, 443-456. doi: 10.1590/S0100-879X2006005 000082

Marangoni, A., Sparacino, M., Cavrini, F., Storni, E., Mondardini, V., Sambri, V., et al. (2005). Comparative evaluation of three different ELISA methods for the diagnosis of early culture-confirmed Lyme disease in Italy. J. Med. Microbiol. 54, 361-367. doi: 10.1099/jmm.0. 45853-0

Margos, G., Piesman, J., Lane, R. S., Ogden, N. H., Sing, A., Straubinger, R. K., et al. (2014). Borrelia kurtenbachii sp. nov.: a widely distributed member of the Borrelia burgdorferi sensu lato species complex in North America. Int. J. Syst. Evol. Microbiol. 64, 128-130. doi: 10.1099/ijs.0.054593-0

Mavin, S., Evans, R., Milner, R. M., Chatterton, J. M. W., and Ho-Yen, D. O. (2009). Local Borrelia burgdorferi sensu stricto and Borrelia afzelii strains in a single mixed antigen improves Western blot sensitivity. J. Clin. Pathol. 62, 552-554. doi: 10.1136/jcp.2008. 063461

Mavin, S., Milner, R. M., Evans, R., Chatterton, J. M. W., Joss, A. W. L., and Ho-Yen, D. O. (2007). The use of local isolates in Western blots improves serological diagnosis of Lyme disease in Scotland.
J. Med. Microbiol. 56, 47-51. doi: 10.1099/jmm.0. 46793-0

Miklossy, J. (2012). Chronic or late Lyme neuroborreliosis: analysis of evidence compared to chronic or late neurosyphilis. Open Neurol. J. 6, 146-157. doi: 10.2174/1874205X01206 010146

Murgia, R., and Cinco, M. (2004). Induction of cystic forms by different stress conditions in Borrelia burgdorferi. APMIS 112, 57-62. doi: 10.1111/j.1600-0463.2004.apm1 120110.x

Nicolle, C. (1993). "Destin des maladies infectieuses (in French)," in Reedited by the Association des ed France Lafayette (Paris: Anciens Elèves de l'Institut Pasteur), 216.

Nields, J. A., and Kveton, J. F. (1991). Tullio phenomenon and seronegative Lyme borreliosis. Lancet 338, 128-129. doi: 10.1016/01406736(91) $90130-\mathrm{H}$

Ogden, N. H., Margos, G., Aanensen, D. M. Drebot, M. A., Feil, E. J., Hanincova, K., et al. (2011). Investigation of genotypes of Borrelia burgdorferi in Ixodes scapularis ticks collected during surveillance in Canada. Appl. Environ. Microbiol. 77, 3244-3254. doi: 10.1128/AEM. 02636-10

Perronne, C. (2012). Lyme disease antiscience. Lancet Infect. Dis. 12, 361-362. doi: 10.1016/S14733099(12)70053-1

Phillips, S. E., Mattman, L. H., Hulinska, D., and Moayad, H. (1998). A proposal for the reliable culture of Borrelia burgdorferi from patients with chronic Lyme disease, even from those previously aggressively treated. Infection 26, 364-367. doi: 10.1007/BF02770837

Rizzoli, A., Hauffe, H. C., Carpi, G., Vourc'h, G. I., Neteler, M., and Rosà R. (2011). Lyme borreliosis in Europe. Eurosurveillance 16, 1-8.

Roche-Lanquetot, M. O., Ader, F., Durand, M C., Carlier, R., Defferière, H., Dinh, A., et al. (2008). Results of a prospective standardized study of 30 patients with chronic neurological and cognitive disorders after tick bites (in French). Med. Mal. Infect. 38, 543-548. doi: 10.1016/j.medmal.2008.06.007

Rudenko, N., Golovchenko, M., and Grubhoffer, L., Oliver, J. H. Jr. (2011). Updates on Borrelia burgdorferi sensu lato complex with respect to public health. Ticks Tick Borne Dis. 2, 123-128. doi: 10.1016/j.ttbdis.2011.04.002

Rudenko, N., Golovchenko, M., Ruzek, D., Piskunova, N., Mallatova, N., and Grubhoffer, L. (2009). Molecular detection of Borrelia bissettii DNA in serum samples from patients in the Czech Republic with suspected borreliosis. FEMS Microbiol. Let. 292, 274-281. doi: 10.1111/j.1574-6968.2009. 01498.x

Schutzer, S. E., Coyle, P. K., Belman, A. L., Golightly, M. G., and Drulle, J. (1990). Sequestration of antibody to Borrelia burgdorferi in immune complexes in seronegative Lyme disease. Lancet 335 , 312-315. doi: 10.1016/0140-6736(90) 90606-6

Schwan, T. G., Anderson, J. M., Lopez, J. E., Fischer, R. J., Raffel, S. J., McCoy, B. N., et al. (2012). Endemic foci of the tick-borne relapsing fever spirochete Borrelia crocidurae in Mali, West Africa, and the potential for human infection. PLoS
Negl. Trop. Dis. 6:e1924. doi: 10.1371/journal.pntd. 0001924

Stanek, G., and Reiter, M. (2011). The expanding Lyme Borrelia complex-clinical significance of genomic species? Clin. Microbiol. Infect. 17, 487-493. doi: 10.1111/j.1469-0691.2011. 03492. $\mathrm{x}$

Straubinger, R. K. (2000). PCR-based quantification of Borrelia burgdorferi organisms in canine tissues over a 500-day postinfection period. J. Clin. Microbiol. 38, 2191-2199.

Straubinger, R. K., Summers, B. A., Chang, Y. F., and Appel, M. J. (1997). Persistence of Borrelia burgdorferi in experimentally infected dogs after antibiotic treatment. J. Clin. Microbiol. $35,111-116$.

Stricker, R. B., and Johnson, L. (2014). Lyme disease: call for a "Manhattan Project" to combat the epidemic. PLoS Pathog. 10:e1003796. doi: 10.1371/journal.ppat.1003796

Strle, F., and Stanek, G. (2009). Clinical manifestations of Lyme borreliosis. Curr. Probl. Dermatol. 37, 51-110. doi: 10.1159/000213070

Tager, F. A., Fallon, B. A., Keilp, J., Rissenberg, M., and Ray Jones, C., Liebowitz, M. R. (2001). A controlled study of cognitive deficits in children with chronic Lyme disease. J. Neuropsychiatry Clin. Neurosci. 13, 500-507. doi: 10.1176/appi.neuropsych. 13.4 .500

Tveitnes, D., Oymar, K., and Natas, O. (2009). Laboratory data in children with Lyme neuroborreliosis, relation to clinical presentation and duration of symptoms. Scand. J. Infect. Dis. 41, 355-362. doi: 10.1080/0036554090 2787666

Varela, A. S., Luttrell, M. P., Howerth, E. W., Moore, V. A., Davidson, W. R., Stallknecht, D. E., et al. (2004). First culture isolation of Borrelia lonestari, putative agent of Southern tick-associated rash illness. J. Clin. Microbiol. 42:1163-1169. doi: 10.1128/JCM.42.3.11631169.2004

Vayssier-Taussat, M., Moutailler, S., Michelet, L., Devillers, E., Bonnet, S., Cheval, J., et al. (2013). Next generation sequencing uncovers unexpected bacterial pathogens in ticks in Western Europe. PLoS ONE 8:e81439. doi: 10.1371/journal.pone. 0081439

Wallet, F., Labalette, P., Herwegh, S., Loïez, C., Margaron, F., and Courcol, R. J. (2008). Molecular diagnosis of a bilateral panuveitis due to Borrelia burgdorferi sensu lato by cerebral spinal fluid analysis. J. Infect. Dis. 61, 214-215.

Wojciechowska-Koszko, I., Maczynska, I., Szych, Z., and Giedrys-Kalemba, S. (2011). Serodiagnosis of borreliosis: indirect immunofluorescence assay, enzyme-linked immunosorbent assay and immunoblotting. Arch Immunol. Ther. Exp. 59, 69-77. doi: 10.1007/s00005-0100111-0

Wormser, G. P. (2006). Early Lyme disease. N. Engl. J. Med. 354, 2794-2801. doi: 10.1056/NEJMcp061181

Wormser, G. P., Dattwyler, R. J., Shapiro, E. D., Halperin, J. J., Steere, A. C., Klempner, M. S., et al. (2006). The clinical assessment, treatment, 
and prevention of Lyme disease, human granulocytic anaplasmosis, and babesiosis: clinical practice guidelines by the Infectious Diseases Society of America. Clin. Infect. Dis. 43, 1089-1134. doi: 10.1086/508667

Yrjänäinen, H., Hytönen, J., Hartiala, P., Oksi, J., and Viljanen, M. K. (2010). Persistence of borrelial DNA in the joints of Borrelia burgdorferiinfected mice after ceftriaxone treatment. APMIS 118, 665-673. doi: 10.1111/j.1600-0463.2010. 02615.x
Conflict of Interest Statement: The author declares that the research was conducted in the absence of any commercial or financial relationships that could be construed as a potential conflict of interest.

Received: 25 March 2014; accepted: 19 May 2014; published online: 03 June 2014.

Citation: Perronne C (2014) Lyme and associated tickborne diseases: global challenges in the context of a public health threat. Front. Cell. Infect. Microbiol. 4:74. doi: 10.3389/fcimb.2014.00074
This article was submitted to the journal Frontiers in Cellular and Infection Microbiology.

Copyright (c) 2014 Perronne. This is an open-access article distributed under the terms of the Creative Commons Attribution License (CC BY). The use, distribution or reproduction in other forums is permitted, provided the original author(s) or licensor are credited and that the original publication in this journal is cited, in accordance with accepted academic practice. No use, distribution or reproduction is permitted which does not comply with these terms. 